\title{
The Production of Airblast From Solid Rocket Motor Fallbacks
}

J. E. Reaugh, E. L. Lee, J. L. Maienschein

September 14, 2012 
This document was prepared as an account of work sponsored by an agency of the United States government. Neither the United States government nor Lawrence Livermore National Security, LLC, nor any of their employees makes any warranty, expressed or implied, or assumes any legal liability or responsibility for the accuracy, completeness, or usefulness of any information, apparatus, product, or process disclosed, or represents that its use would not infringe privately owned rights. Reference herein to any specific commercial product, process, or service by trade name, trademark, manufacturer, or otherwise does not necessarily constitute or imply its endorsement, recommendation, or favoring by the United States government or Lawrence Livermore National Security, LLC. The views and opinions of authors expressed herein do not necessarily state or reflect those of the United States government or Lawrence Livermore National Security, LLC, and shall not be used for advertising or product endorsement purposes.

This work performed under the auspices of the U.S. Department of Energy by Lawrence Livermore National Laboratory under Contract DE-AC52-07NA27344. 


\title{
THE PRODUCTION OF AIRBLAST FROM SOLID ROCKET MOTOR FALLBACKS
}

\author{
J. E. Reaugh, E. L. Lee, J. L. Maienschein \\ Lawrence Livermore National Laboratory \\ Livermore, CA
}

\begin{abstract}
A principal long-range hazard of solid rocket motor fall-backs is the airblast overpressure that breaks windows, and the overpressure-impulse that throws the broken glass. The basis for detailed analyses of airblast, including the effects of local terrain, wind, and temperature gradient, use the TNTequivalent weight as the starting point. A conservative estimate is that all the propellant weight is used to produce airblast, and that the propellant is 1.3 times as efficient as TNT, in accord with its energy density. Historic fall-backs of motors using Hazard Class 1.3 propellant, and some large-scale tests of those propellants, have resulted in air-blast inferences or measurements consistent with much less than full yield, even though the propellant was fully consumed. Other fall-backs and tests may be consistent with full yield.

We performed direct calculations of the airblast, driven by the time-dependent release of the chemical energy of the propellant. Our calculated results show that the time to burn (or nominal consumption rate) is an important parameter in determining the efficiency of airblast. At one extreme, very slow burning that would occur with unpressurized, unbroken propellant, produces no airblast --the TNT equivalent is zero. As the time to burn decreases, the airblast efficiency increases, reaching a maximum value that can exceed the energy-equivalent 1.3 when the time to burn is in resonance with the air-blast duration. At still less time to burn, the efficiency decreases, reaching the energy-equivalent value when the energy is released in a short time. Our calculations also show that for relatively long times to burn, the TNT equivalent for overpressure is not the same as for impulse.
\end{abstract}

\section{METHOD OF AIRBLAST CALCULATION}

We use the one-dimensional, Lagrange finite-difference computer program ONEDEE ${ }^{1}$ to solve the equations of compressible hydrodynamics with spherical symmetry, using the second-order, explicit finitedifference algorithm of Wilkins. ${ }^{2}$ With this program, we can calculate the airblast from a hemispherical, center-detonated explosive charge placed on a perfectly reflecting ground plane, which is the mathematically identical result to the airblast from an isolated spherical charge with twice the explosive mass suspended in air. By varying the initial density and pressure of the surrounding air, we can account for the effects of altitude and temperature on the blast signature. (In our applications, some of the experimental tests were performed at Edwards AFB, at the approximate altitude of $3000 \mathrm{ft}$.) The calculations reported here are all for air at one standard atmosphere, with density $1.22510^{-3} \mathrm{~g} / \mathrm{cc}$ and pressure 1.01325 bars.

During the course of the calculation, we record the overpressure and optionally the dynamic pressure at positions fixed in space, by interpolating the values from the two Lagrange zones that have moved to surround that position. This is done to mimic the signal recorded by blast gauges, which are mounted near the ground plane, fixed in space while the blast wave washes over them, and which record the lateral pressure, rather than the reflected pressure. The numerical values are saved at regular time intervals for subsequent analysis and plotting.

The airblast measures that are customarily reported are the peak overpressure and the positive phase impulse. An overpressure history from a 5 ton hemispherical TNT explosion, calculated at $700 \mathrm{ft}$ from the source is shown in Figure 1. The impulse is defined as the time integral of the overpressure history taken over the positive phase only. Operationally, it is the peak value of the integral taken to be a function of time. The value is robust with respect to computational zone size and recording interval, and

* This work performed under the auspices of the U. S. Department of Energy by the Lawrence Livermore National Laboratory under contract number W-7405-Eng-48. 
to the frequency response of experimental gauges. It is, however, sensitive to experimental gauge hysteresis, since the peak value depends on when the overpressure starts into the negative phase. The peak overpressure is more sensitive to frequency response. The method we use to report our computational peak value is illustrated in (Figure 2). We record the first five local maxima and minima (peaks and valleys) and average the adjacent peak-valley pairs in overpressure and time. Those five points are fit by linear regression. The intercept of that line with the time-of-arrival, which we take to be the time when the overpressure attains half the value of the first peak, is reported as the peak overpressure.

The origin of the peaks and valleys, and their prominence in our calculation, is the result of choices of finite-difference program parameters that are not usually made. We perform these calculations with a quadratic vonNeumann and Richtmyer artificial viscosity 3 , but with no linear artificial viscosity. 4 Our objective is to calculate the airblast to low overpressure, on the order of $1 \mathrm{psi}(7000 \mathrm{~Pa})$ which requires propagation through typically 1000 finite-difference zones. The use of standard values of linear viscosity results in severe degradation of the pulse (See Figure 3) at long range. Without linear viscosity, however, the dispersion of the finite difference equations is revealed. The spatial discretization results in a wave-length dependence of the phase velocity such that short wavelength components lag behind, resulting in the oscillations that are left. ${ }^{5}$ For our purposes, the solution is converged with respect to zone size. (See Figure 3)

The equation of state for air is a ratio of polynomials fit ${ }^{6}$ to a tabular equation of state for air developed by Graboske. ${ }^{7}$ The results for air taken to be a polytropic gas (adiabatic exponent gamma taken to be 1.4 with the same initial density and pressure) are not significantly different. (Figure 4)

\section{BASELINE RESULTS}

\section{$\underline{\text { SCALING LAWS }}$}

For a specific explosive and given initial state of the background gas, airblast effects follow Cauchy or hydrodynamic scaling. For a change in length scale $\lambda$, the time scales by the same factor $\lambda$, so that the peak overpressure at scaled range $\lambda \mathrm{R}$ is the same, and the overpressure impulse at that range scales by the factor $\lambda$. Since the explosive mass changes by the factor $\lambda^{3}$, the scaled range is the range divided by the cube-root of the explosive weight. This hydrodynamic scaling is referred to as cube-root scaling. If the explosive energy density is changed, an additional scaling parameter is, in principle, introduced. Over the range of energy density exhibited by secondary explosives and propellants, however, there is no discernible effect at the same total energy. This results in energy scaling for explosives and propellants, so that energetic materials are equivalent to the weight of TNT that matches their energy content. For the Class 1.3 rocket propellants of our interest, the weight scaling factor is about 1.3

\section{TNT DETONATION}

Although TNT is not oxygen balanced, so that late-time combustion occurs as air mixes with the TNT detonation products across the Taylor-unstable interface, the time scale of that mixing is slow relative to blast generation in open air. Thus the airblast is consistent with the energy released by detonating TNT in an inert atmosphere. Regardless of whether of not TNT is the theoretically desirable standard, it has long been the standard for reporting airblast, in part because of data from a number of large (100 to 500 ton) TNT explosive tests, which are the historic basis for the various airblast correlations.

We used a JWL equation of state, ${ }^{8}$ for TNT using coefficients recorded by Souers. ${ }^{9}$ In g-cm- $\mu$ sec units the values for the JWL coefficients A, B, $R_{1}, R_{2}$, and $\omega$ are 4.549, $0.1012,4.5,1.5$, and 0.25 The initial density is 1.632 , and the initial energy density is 0.078 We used the programmed burn method, which prescribes the time of arrival of the detonation front to be linear with radius, in accord with a constant detonation velocity. We show the peak overpressure calculated as a function of range, and the results from CONWEP, 10 which uses the airblast results of Kingery and Bulmash ${ }^{11}$ for an isolated sphere and for a hemispherical surface burst.(Figure 5) In CONWEP, approximately $10 \%$ of the energy of a surface burst is assumed to be used for crater formation, so unavailable for airblast. Our calculations should match the spherical result precisely, and do follow the CONWEP spherical results accurately. 
The comparison for impulse is not as satisfactory. (Figure 6) The impulse we calculate is consistent with CONWEP impulse from about $80 \%$ yield. We examined some of the historic data from large-yield (100 and 500 ton) TNT tests ${ }^{12-16}$ These yields are consistent with our interest in fallbacks of rocket motor segments with weights exceeding 100 tons. We scaled the 500 ton data to 100 tons. Comparison of the peak overpressure with both the CONWEP isolated sphere and hemispherical surface burst (Figure 7) shows that both curves are representative of the data median, especially in the range of our interest, which is less than 10 psi. The comparison with impulse, however (Figure 8) shows the CONWEP result to be biased to the high end of the data span, rather than the median. This is due, in part, to the development of the CONWEP curves. Since the intended use of CONWEP is to estimate the airblast environment for structural response, the conservatism is understandable.

\section{ENERGY RELEASE RATE}

We performed a series of calculations with the original hemispherical mass of 5 tons and with the same total energy. In each calculation we chose the value of the time to burn, $\mathrm{T}$, and released the energy at a uniform rate over that time, and uniformly in the expanding volume that contains the explosive products. For these calculations we treated the product zones as a gamma-law gas, and used the value 1.25 , consistent with the large-volume behavior of the JWL equation of state $(\omega=\gamma-1=0.25)$. We recorded the overpressure history at ranges 300,500 , and $700 \mathrm{ft}$. For each value of T we calculated the TNT weight that, according to CONWEP, would give the same peak overpressure (Pressure-based yield) or the same overpressure impulse (Impulse-based yield). We calculate the relative yield by dividing by the corresponding CONWEP yield for our TNT detonation. We show the relative yield (Figure 9) as a function of the time to burn. With the usual scaling rules, the time to burn for a different value of the explosive weight should be compared at the same scaled time $\left(\mathrm{T} / \mathrm{W}^{1 / 3}\right)$.

The curves based on impulse are apparently independent of range. At relatively short times, the equivalent yield is that of a TNT detonation. For the value $\gamma=1.25$, the relative yield decreases significantly and monotonically as the time to burn increases. When we changed the adiabatic exponent of the energetic material products to be 1.5, we achieve a relative yield greater than one in the band of energy release times that approximates the positive phase duration. The adiabatic exponent of partly reacted propellant at relatively modest pressure but relatively high temperature is not well known. As a consequence, this represents an uncertainty in the apparent yield if the time to burn is in this range. At short times to burn, the relative yield is one. At long times to burn, the relative yield is zero.

The results based on peak overpressure are more complicated. In an intermediate range of energy release times, the inferred yield curve is no longer monotonic. Instead, there are sudden, large changes as a function of deposition time. Closer examination of the overpressure histories at 50 millisec duration illustrate what is happening. The sphere of product gas rings during the time of energy release. For a detonation (Figure 1) the recompressions are in the negative phase, and remain well behind the shock front. They are caused by the products overexpanding to less than one atmosphere, and then recompressing, which drives secondary and tertiary shocks into the already shocked air. When energy is still being released during this time, the recompression is in the positive phase. A second pressure pulse (Figure 10) at the $300 \mathrm{ft}$ range, is seen to catch up to the shock front by the time the shock reaches $700 \mathrm{ft}$. As a consequence, the peak-pressure determined apparent yield is larger at $700 \mathrm{ft}$ than at $300 \mathrm{ft}$.

Comparison of the relative yield (Figure 9) shows that the yield inferred from impulse is 2-3 times the value of the yield inferred from overpressure at the intermediate times to burn. This difference is a consequence of the non-ideal airblast overpressure histories. The pressure recorded at $700 \mathrm{ft}$ from an energy release over 200 millisec is shown in Figure 11. It is qualitatively unlike the classic wave form shown in Figure 1.

\section{APPLICATION TO FALLBACKS}

If a 100 ton rocket motor segment, as a consequence of a fallback, burns up in less than about 50 millisec (20 millisec for the 5 ton source of Figure 9) then the equivalent TNT yield will be approximately that of the energy equivalent detonation, 130 tons of TNT. If, instead, it releases energy over 500 millisec (200 millisec for the 5 ton object) then the equivalent TNT yield will be less than 25 tons, and will exhibit a non-ideal wave form. There is an intermediate range of burn-up times for which, depending on the effective gamma of the combustion products, the equivalent yield can exceed the energy equivalent value. 
The time required for burn-up of these propellants in fallback accidents depends on the fragmentation that results from impact and on the pressure dependent burn rate. The fragmentation increases surface area, which increases the mass burn rate. The smallest overall dimension of the propellant segment or piece determines the confinement time over which the mass burn rate can operate. Companion papers at this conference describe our measurements of the laminar burn rate, ${ }^{17}$ and our model to describe the interaction of mechanical fragmentation with mass burn rate. ${ }^{18}$

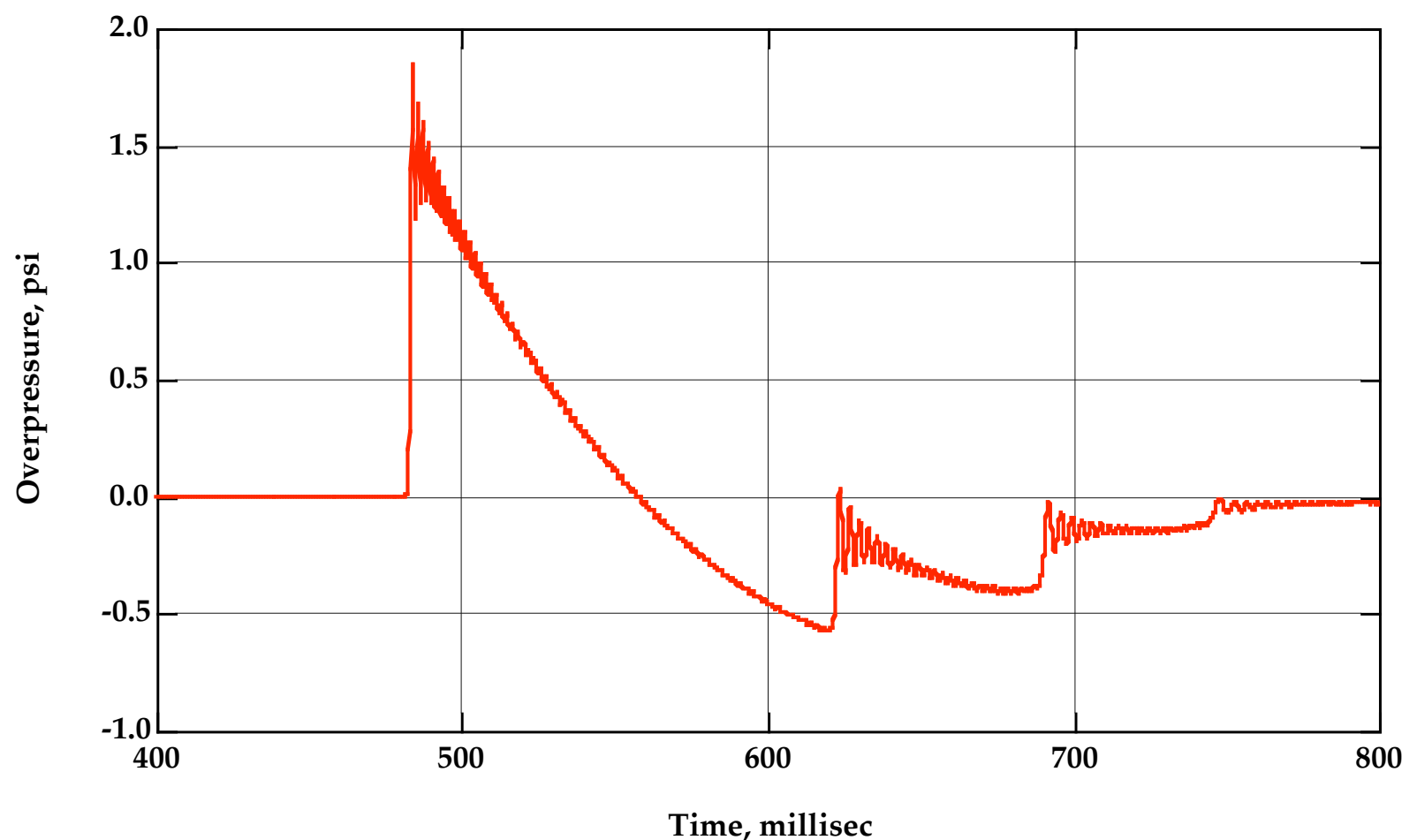

Figure 1. Overpressure history calculated for a 5 ton TNT explosion recorded $700 \mathrm{ft}$ from the source. 


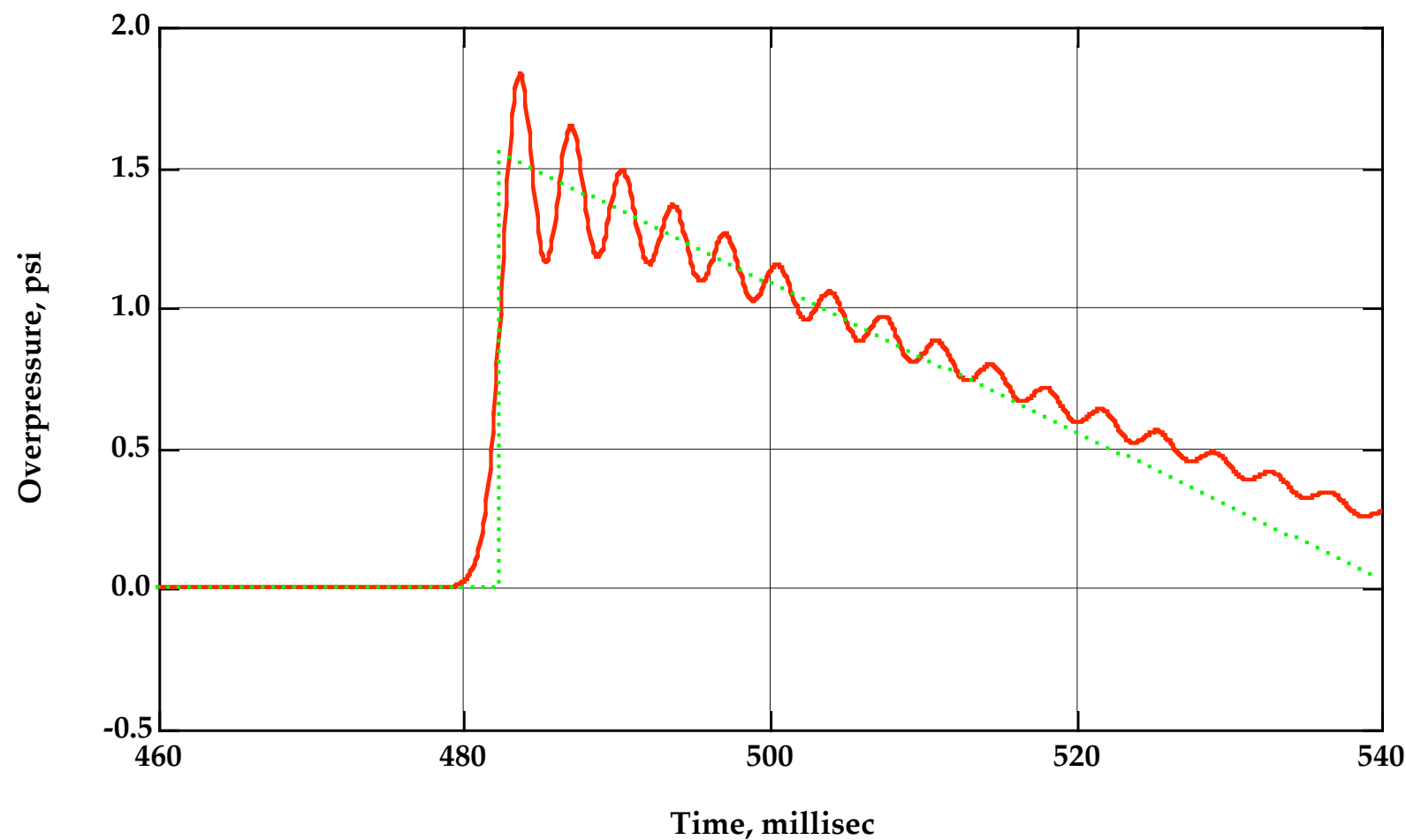

Figure 2. Method used to calculate peak overpressure from the waveform shown in Figure 1.

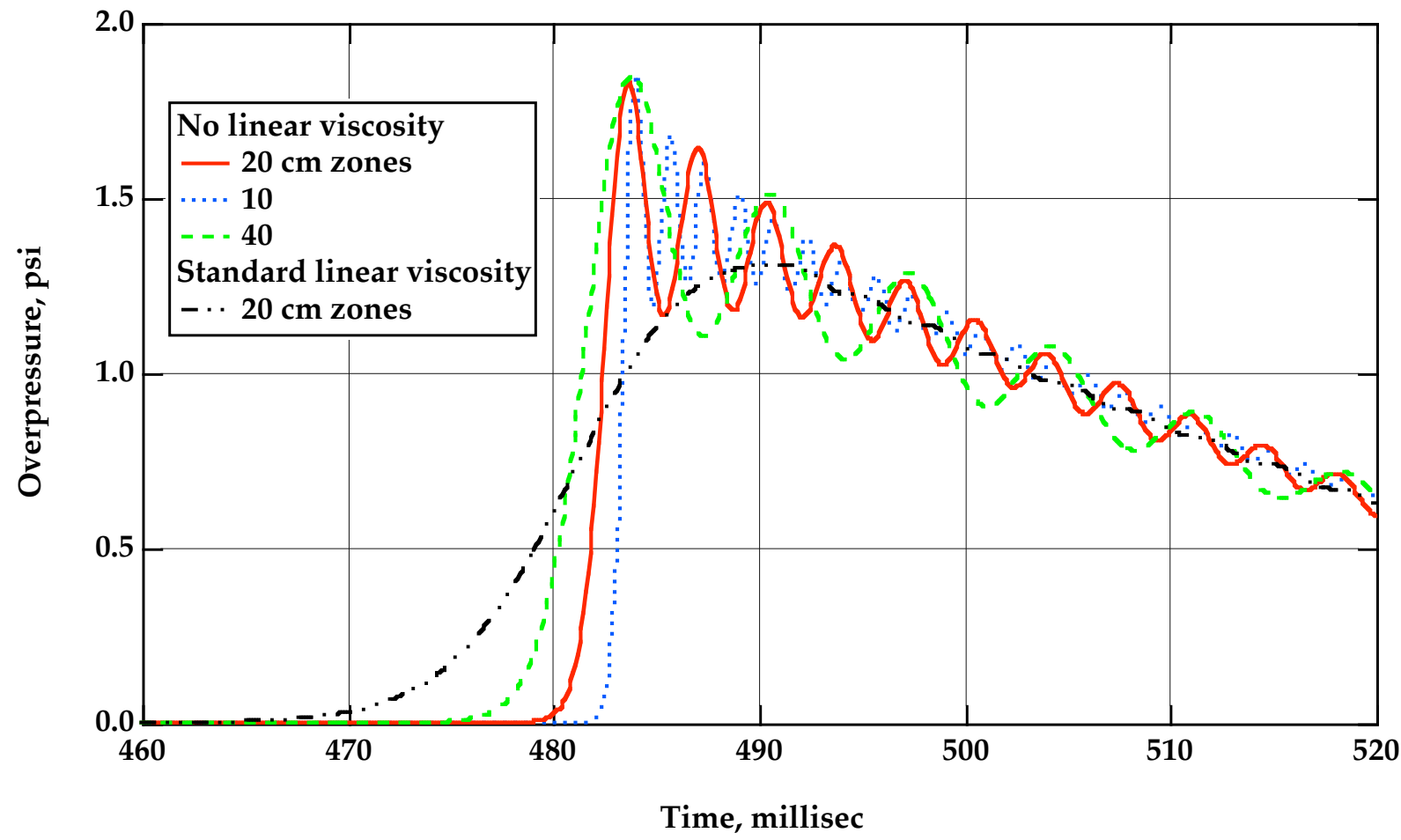

Figure 3. Overpressure history calculated with standard linear viscosity, and with half and twice the nominal zone size 


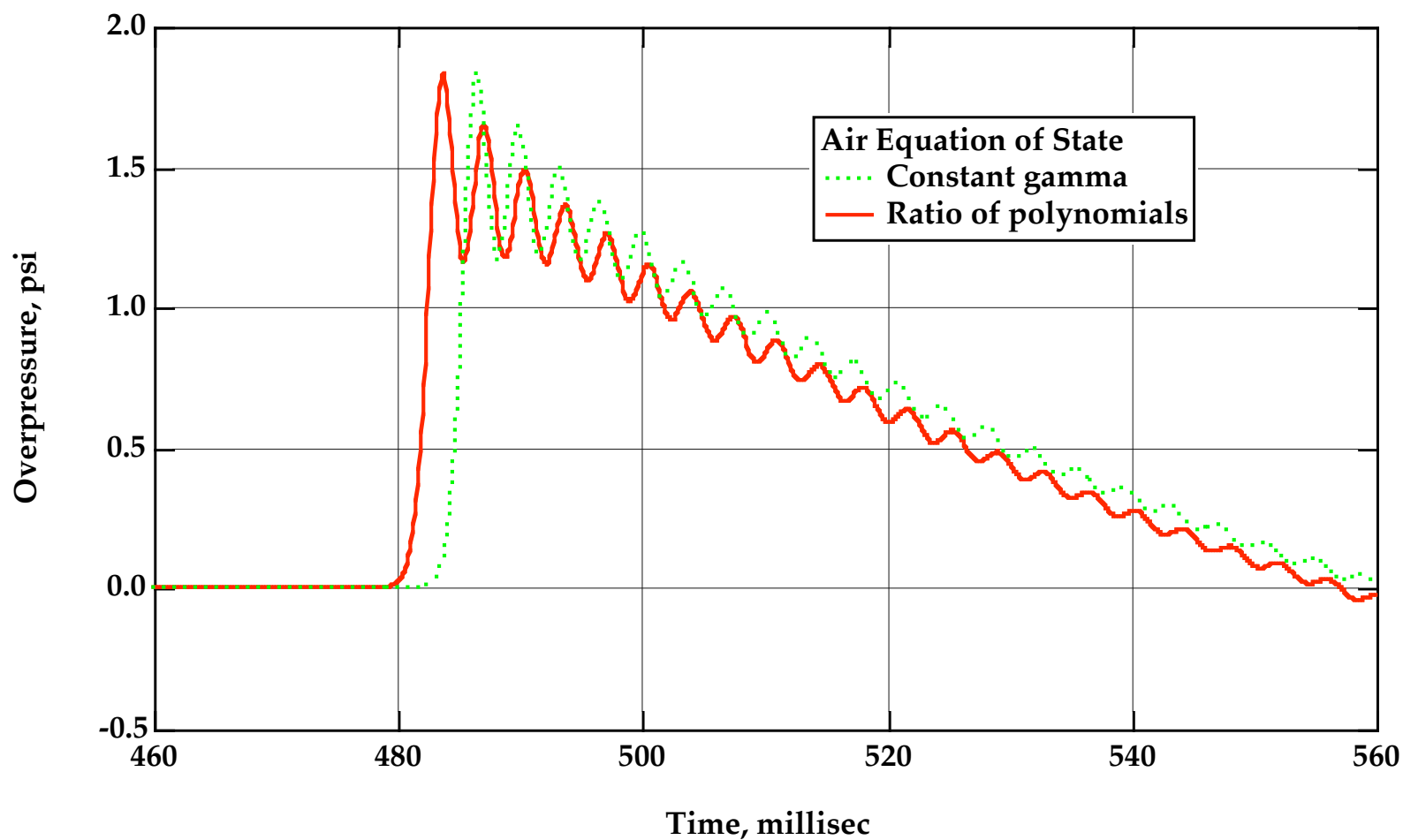

Figure 4. Overpressure calculated in air using the constant gamma and the ratio of polynomials equations of state.

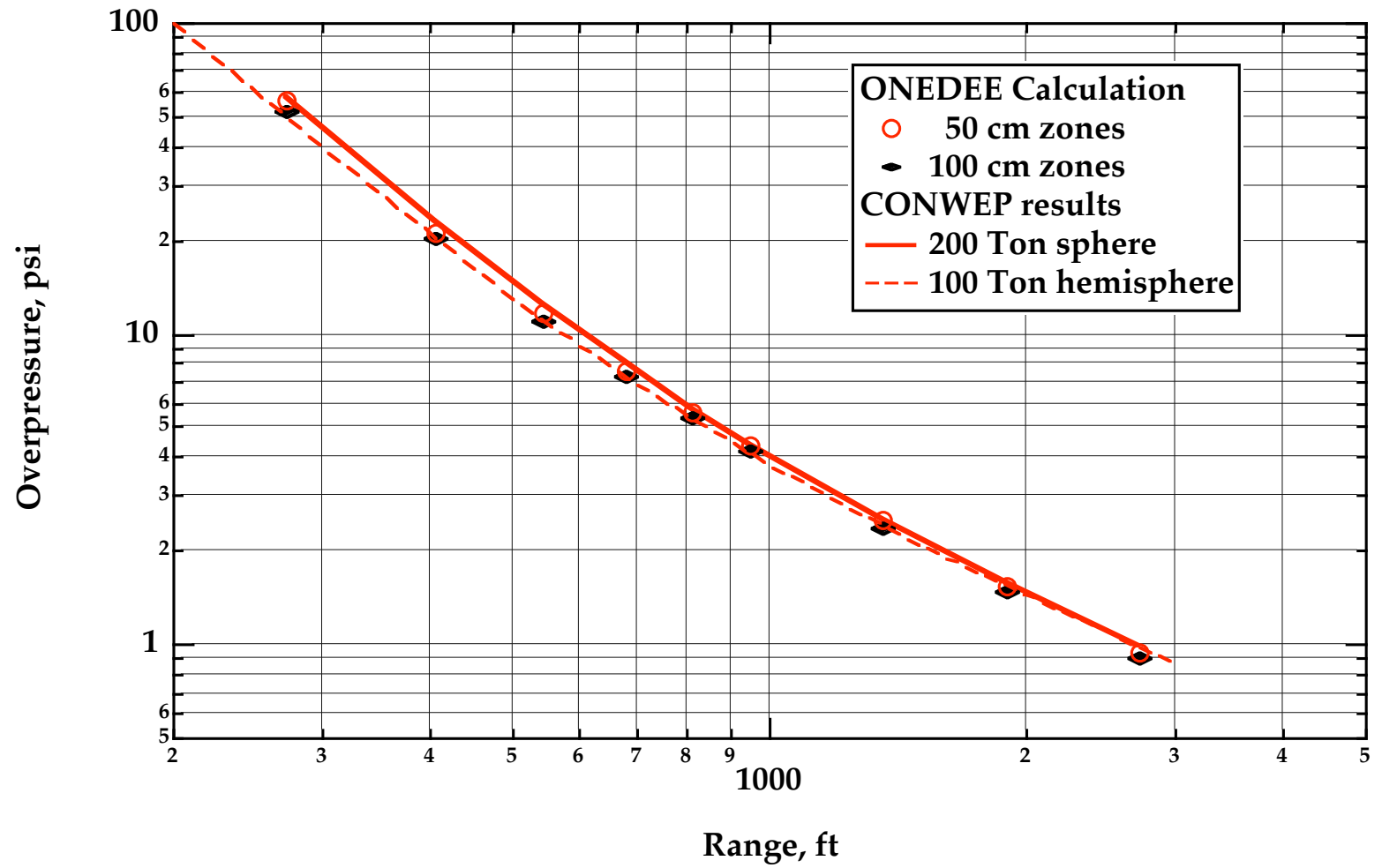

Figure 5. Peak overpressure calculated in air and CONWEP results for a sphere in free air and for a hemispherical surface burst 


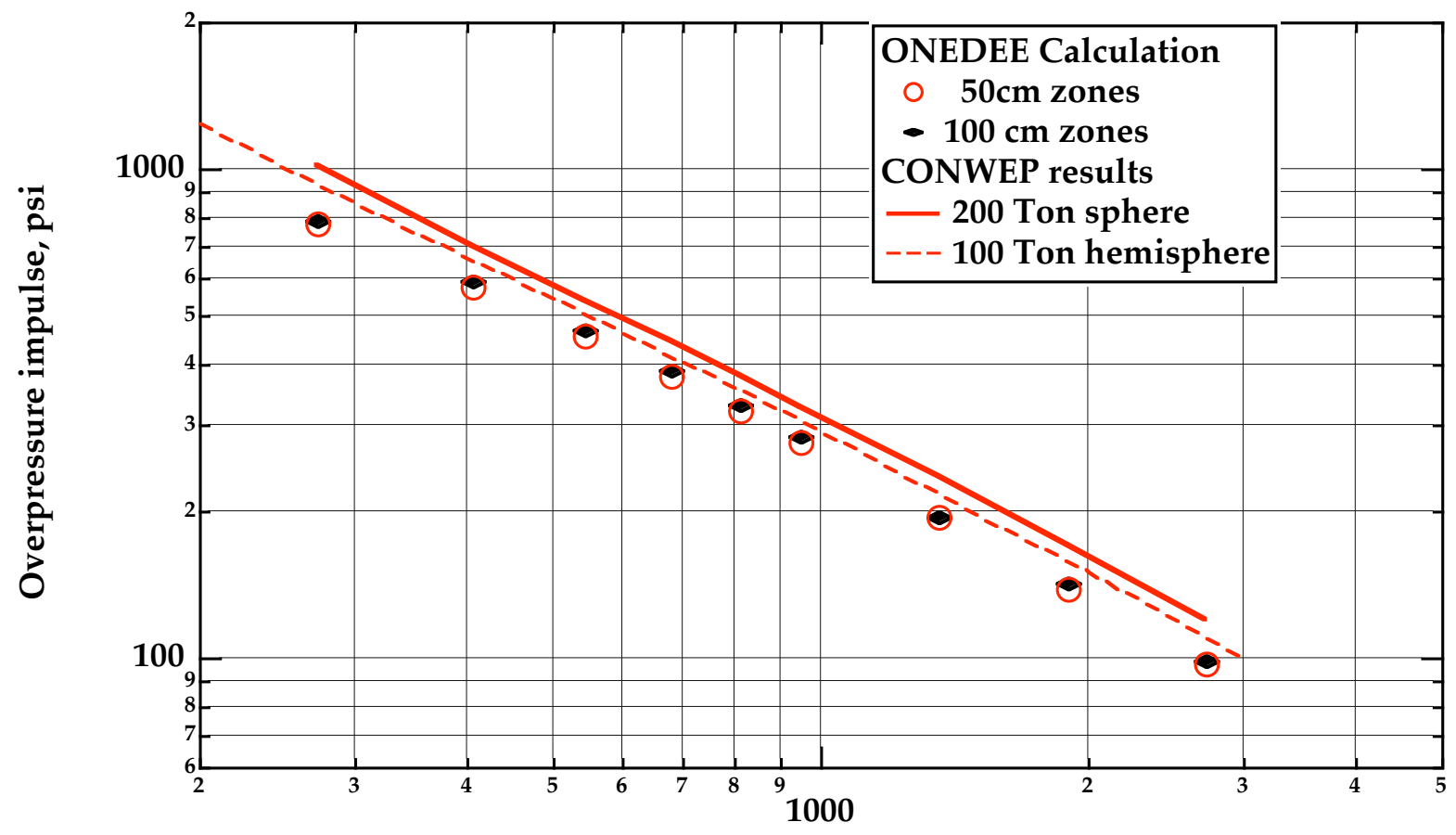

Range, $\mathrm{ft}$

Figure 6. Positive phase impulse calculated in air and CONWEP results for both a sphere in free air and a hemispherical surface burst

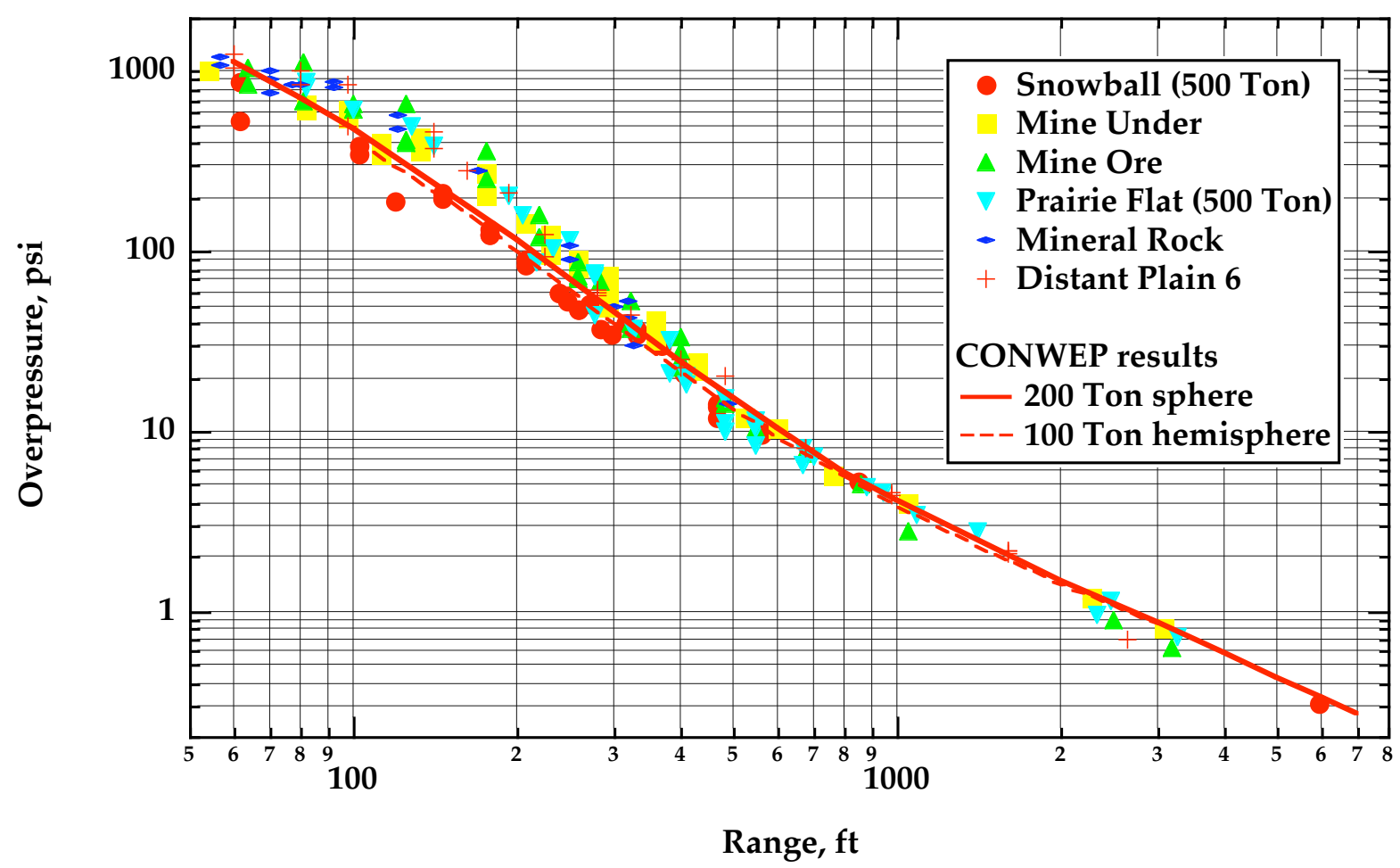

Figure 7. Experimental overpressure from a number of large TNT explosions scaled to 100 tons, and the CONWEP fitted curve. 


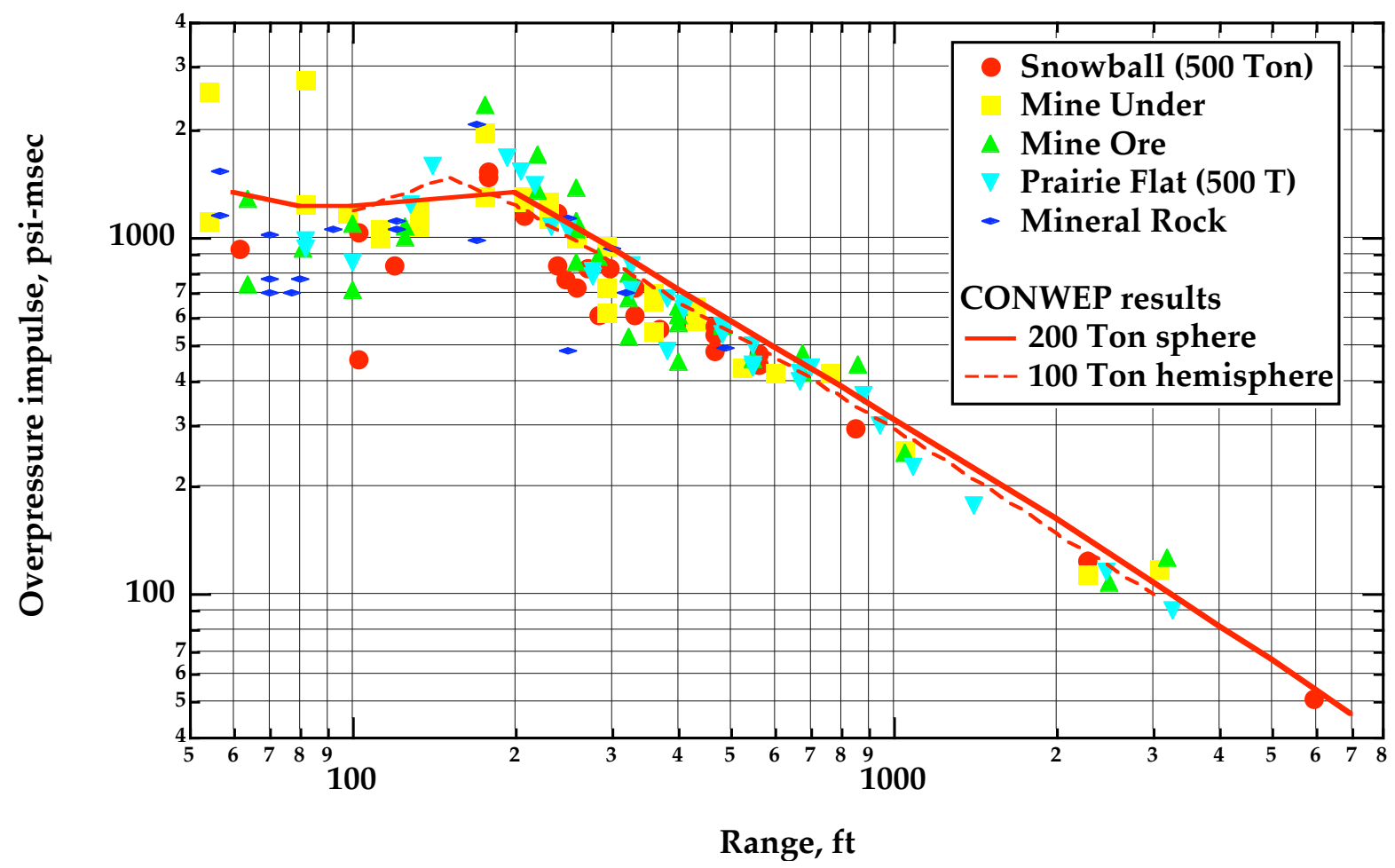

Figure 8. Experimental positive phase impulse from a number of large TNT explosions, and the CONWEP fitted curves

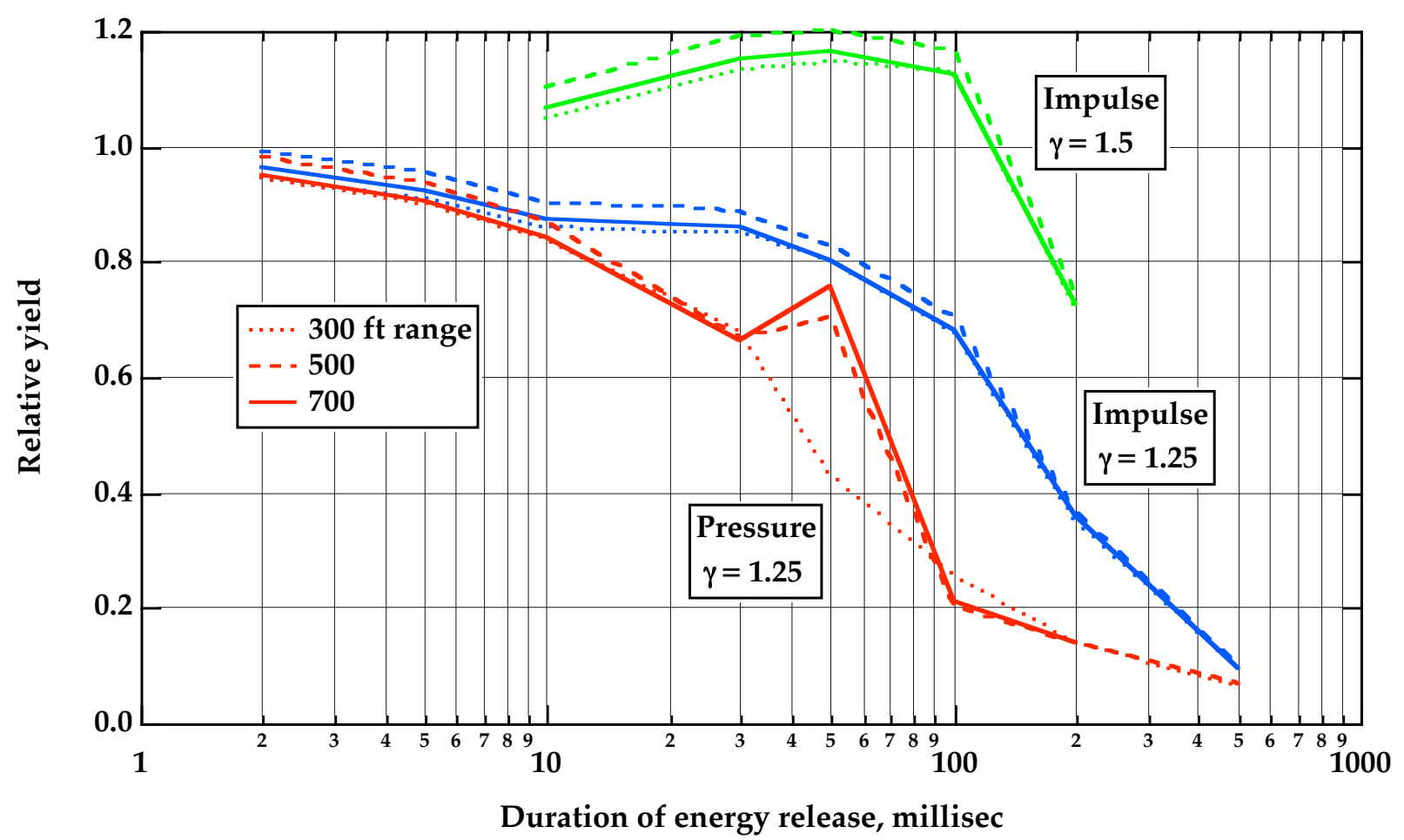

Figure 9. Calculated relative yield based on peak overpressure and on impulse from a 5-ton surface burst with the energy released uniformly over time. 


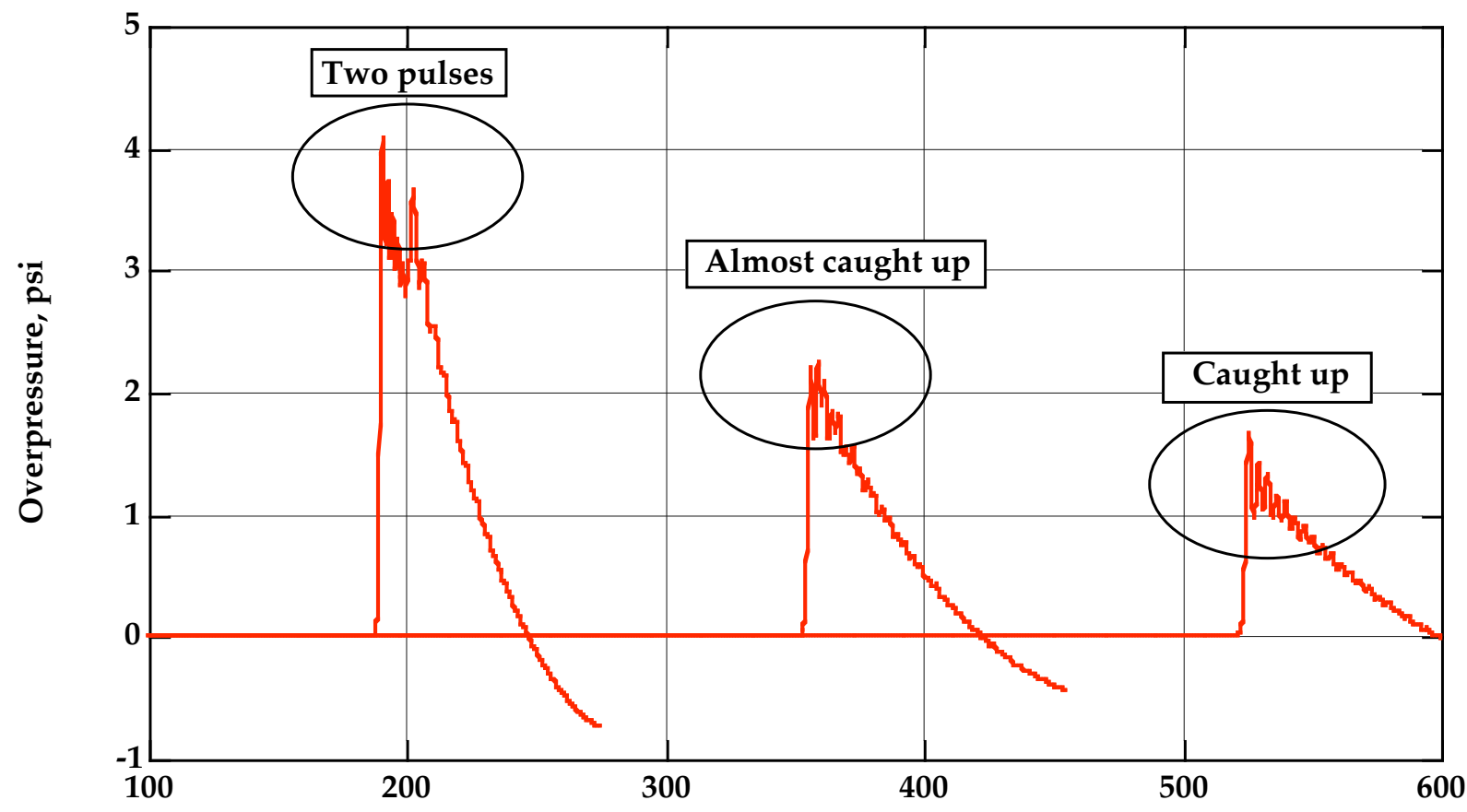

Time, millisec

Figure 10. Overpressure history at 300, 500, and $700 \mathrm{ft}$ from a 50 millisec energy release rate in 5 tons. The structure of the wave caused by pressure oscillations in the cloud of products during energy release eventually catches up to the shock front, and reinforces the initial shock.

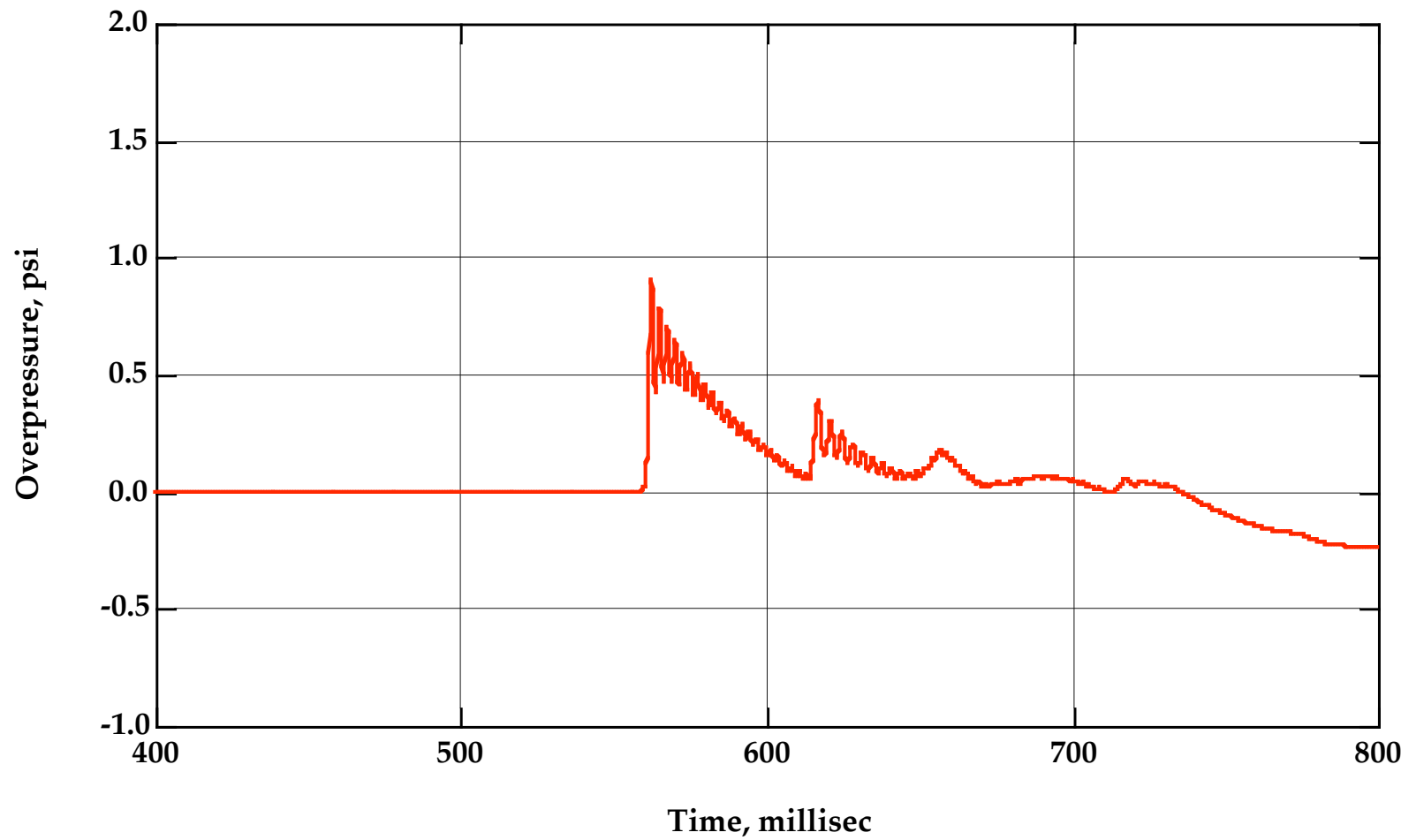

Figure 11. Overpressure history at $700 \mathrm{ft}$ from a 5 ton source that takes 200 millisec to burn. The airblast is qualitatively different from the classical airblast shown in Figure 1. 


\section{CONCLUSIONS}

Our analyses reveal that the standard tables for airblast are not sufficient to evaluate the effects of slower energy releases in propellant explosions. In particular, overpressure effects can be significantly greater than standard analysis would predict under certain combinations of range and energy release rate. Impulse effects are also present, but differ in their dependence on range. We recommend that the results shown here be carefully considered in launch-vehicle safety assessments.

\section{REFERENCES}

1. J. E. Reaugh, “ONEDEE, a One-dimensional Lagrange Code to Solve the Equations of KO," , 1982. 2. M. L. Wilkins, "Calculation of Elastic-Plastic Flow," in Methods of Computational Physics, vol. 3, B. Alder, S. Fernbach, and M. Rotenberg, Eds. New York: Academic, 1964, pp. 211-263.

3. J. vonNeumann and R. D. Richtmyer, "A method for the numerical calculation of hydrodynamic shocks," J. Appl. Phys., vol. 21, pp. 232-237, 1950.

4. M. L. Wilkins, "Use of Artificial Viscosity in Multidimensional Fluid Dynamic Calculations," J. Comp. Phys., vol. 36, pp. 281-303, 1980.

5. R. D. Richtmyer and K. W. Morton, Difference Methods for Initial Value Problems, 2 ed. New York: Interscience, 1967.

6. R. Tipton, "CALE User's Manual," Lawrence Livermore National Laboratory, Livermore, CA Report No. January 1, 1995.

7. H. C. Graboske, " A New EOS for Air," Lawrence Livermore National Laboratory, Livermore, CA, HDivision Quarterly Report Report No. UCRL-50028-75-2, April through June, 1975.

8. J. W. Kury, H. C. Hornig, E. L. Lee, J. L. McDonnel, D. L. Ornellas, M. Finger, F. M. Strange, and M. L. Wilkins, "Metal acceleration by chemical explosives," presented at Fourth Symposium (International) on Detonation, U. S. Naval Ordnance Laboratory, White Oak, MD, 1965.

9. P. C. Souers, B. Wu, and L. C. Haselman, “Detonation equation of state at LLNL, 1995," Lawrence Livermore National Laboratory, Livermore, CA Report No. UCRL-ID-119262 Rev. 3, February 1, 1996. 10. D. W. Hyde, "CONWEP Conventional Weapons Effects," . Washington, DC: U. S. Army Corps of Engineers Attn: CEEC-ET, 1988.

11. C. N. Kingery and G. Bulmash, "Airblast Parameters from TNT Spherical Air Burst and

Hemispherical Surface Burst," Report No. ARBL-TR-0255, April, 1984.

12. R. E. Reisler, J. H. Keefer, and L. Giglio-Tos, "Basic air blast measurements from a 500-ton TNT detonation: Project 1.1 Operation Snowball," Ballistic Research Laboratories, Aberdeen Proving Ground, ND, Memorandum report Report No. 1818, December, 1966.

13. R. E. Reisler, "Events 5, 6a, and 6 Project 1.01 Air Blast Measurements," presented at Operation Distant Plain Symposium II, Vicksburg, MS, 1968.

14. G. D. Teel, "Airblast Measurements (Mine Under - Mine Ore)," Ballistic Research Laboratories, Aberdeen Proving Ground, MD Report No. 1477, February, 1970.

15. G. D. Teel, "Airblast measurements from a 100 ton TNT detonation over granite - Mineral Rock Event, Mine Shaft Series," Ballistic Research Laboratories, Aberdeen Proving Ground, MD Report No. 1502 (Mine Shaft report MS 2165), October, 1970.

16. L. Giglio-Tos and B. A. Pettit, "Middle North Series, Prairie Flat Event, Project Officers Repoort, project LN-101, Fundamental Blast studies," Ballistic Research Laboratories, Aberdeen Proving Ground, MD, Project officers report Report No. POR-2100 (WT-2100), March 1, 1971.

17. J. L. Maienschein and J. Chandler, "High Pressure Laminar Burn Rates of AP/Al/HTPB Propellants," presented at this conference, 1997.

18. J. L. Maienschein, E. L. Lee, J. E. Reaugh, C. I. Merrill, and R. R. Lambert, "Modeling the Impact Response of Booster Propellants," presented at this conference, 1997. 